\title{
Association between the Asp299Gly Polymorphisms in the Toll-like Receptor 4 and Premature Births in the Finnish Population
}

\author{
EVA LORENZ, MIKKO HALLMAN, RIITTA MARTTILA, \\ RITVA HAATAJA, AND DAVID A. SCHWARTZ \\ Department of Internal Medicine, Section of Infectious Diseases, Wake Forest University School of \\ Medicine, Winston-Salem, North Carolina 27157, U.S.A. [E.L.]; Department of Pediatrics and Biocenter \\ Oulu, University of Oulu, Oulu, Finland 90014 [M.H., R.H.]; Hospital of Seinäjoki, Seinäjoki, Finland \\ 60220 [R.M]; Department of Medicine and the Department of Veterans Affairs Medical Center at Duke \\ University Medical Center, Durham, North Carolina 27710, U.S.A. [D.A.S]
} \begin{abstract}
ABST
Premature birth causes significant health risks of the neonate
and increases the cost for neonatal care. Urogenital infection, often caused by Gram-negative bacteria, is a known risk factor. Toll-like receptor-4 (TLR4) is the major endotoxin-signaling receptor and as such is crucial for the initiation of the innate immune response against Gram-negative bacteria. Recently, a variant in the human TLR4 gene was shown to be associated with impaired receptor function and an increased likelihood of Gramnegative sepsis. In the present study, we determined whether the same polymorphism in TLR4 gene is associated with an increased risk for premature birth. We analyzed genotypes for a Finnish study population consisting of a total of 351 term infants and 440 premature infants (gestational age $<35 \mathrm{wk}$; 282 singletons, 158 multiples) and 94 mothers for the presence of the TLR4 polymorphisms Asp299Gly and Thr399Ile. These polymorphisms were in linkage disequilibrium. The 299Gly allele frequencies were $10.6 \%$ (93 of 880 ) in premature infants and $8.3 \%$ (58 of 72) in term infants. Excluding multiple pregnancies that
\end{abstract}

often result in premature births, $23.8 \%$ (67 of 282) of premature infants and $24.2 \%$ (15 of 62 ) of the mothers of premature infants compared with $15.9 \%$ (55 of 345 ) of term infants and $15.0 \%$ (3 of 20) of the mothers delivering at term were carriers of the TLR4 variant. The frequencies of 299Gly allele and Asp/Gly or Gly/Gly genotype carrier status in premature singleton infants were higher than in term singleton infants $(p=0.024, p=0.028$, respectively) or in premature multiples ( $p=0.036, p=0.044$, respectively). According to the present results an allelic variation in the TLR4 receptor was associated with increased risk of premature birth. (Pediatr Res 52: 373-376, 2002)

TLR4, Toll-like receptor-4

\section{Abbreviations}

TLR2, Toll-like receptor-2

LPS, lipopolysaccharide (endotoxin)

PPROM, preterm premature rupture of fetal membranes RDS, respiratory distress syndrome
Premature birth is a common health problem, responsible for the majority of deaths and nearly half of the congenital neurologic disabilities in the newborn. Ascending infection or chorioamnionitis occur in up to $80 \%$ of all very early premature births (1). The infections often originate from the urinary or intestinal tract. The inflammatory response of placental tissues to microbes is considered to play a prominent role in the pathogenesis of premature labor and birth $(1,2)$.

Received February 6, 2002; accepted April 15, 2002.

Correspondence and reprint requests: Eva Lorenz, Ph.D., Department of Medicine, Section of Infectious Diseases, Wake Forest University, School of Medicine, Medical Center Boulevard, Winston-Salem, NC 27157, U.S.A.; e-mail: elorenz@wfubmc.edu

Supported by grants from Veterans Affairs Administration (E.L.), the Finnish Academy (M.H.), and the Biocenter Oulu (M.H., R.H.).

DOI: 10.1203/01.PDR.0000025342.83436.53
LPS, the main component of the cell wall of Gram-negative bacteria, has been shown to elicit an inflammatory response in vivo and in vitro involving macrophages and monocytes $(3,4)$. Inflammation is characterized by increased secretion of cytokines such as tumor necrosis factor- $\alpha$, IL-1, IL-6, and IL-8 (5, $6)$. The molecular events leading to cell recognition and response to LPS are becoming more clearly defined. Recently, the Toll family of proteins has been identified and consists of 10 type 1 transmembrane receptor proteins (7). The Toll proteins share a highly homologous cytoplasmic domain, similar to the IL-1 receptor, a very short transmembrane domain, and an extracellular portion consisting of leucine-rich repeats (8). TLR4 has been shown to be a major LPS-recognition receptor $(9,10)$. In vivo, mouse strains $\mathrm{C} 3 \mathrm{H} / \mathrm{HeJ}$, which has a Pro to His substitution at amino acid 712 of TLR4, and C57BL/10ScCR, which has a deletion of the TLR4 gene and 
does not express TLR4 RNA, are both hyporesponsive to LPS (11). In addition, macrophages and B cells from TLR4-/mice are unable to mount a cellular response to LPS $(12,13)$. In vitro data from transfection of mammalian cell lines further proved that TLR4 is able to enhance the LPS responsiveness of cells, a process augmented by CD14 and leading to activation of transcription factors nuclear factor $\kappa \mathrm{B}(\mathrm{NF} \kappa \mathrm{B})$ and activator protein 1 (AP-1) (14). These findings indicate that TLR4 is a recognition molecule for Gram-negative pathogens and specifically LPS.

We recently demonstrated that specific polymorphisms of TLR4 (Asp299Gly and Thr399Ile) are associated with airway hyporesponsiveness to inhaled LPS in normal human volunteers (15). Mice that contain mutations in TLR4 are hyporesponsive to LPS and are more susceptible to Gram-negative bacterial challenge (11). We have recently shown in humans that carriers of TLR4 receptor mutations have an increased risk of septic shock (Lorenz E, et al., unpublished data). Gramnegative bacteria are a major cause of ascending urogenital infections, and such infections constitute a known risk factor for premature birth $(1,2)$.

We hypothesized that the variation in the TLR4 receptor gene may be associated with decreased or abnormal immune response and predisposition to premature birth. The present aim was to investigate a patient cohort of term and preterm infants from a homogeneous Caucasian population in Finland for polymorphisms in the TLR4 receptor.

\section{METHODS}

Protocol and study population. The present study population was recruited from patients admitted to the Oulu University Hospital, Oulu; the Central Hospital of Southern Ostrobothnia, Seinäjoki; and the University Central Hospital, Tampere, Finland. The ethics committees of the hospitals approved the study protocol. The mothers of the neonates gave written consent for their infants' or their own blood samples to be used in this study. Samples were collected from 440 premature infants born in 1996-1999 and from 351 healthy infants born at term during March and April in 1998 (Table 1). In addition, we examined the relationship between the genotype of TLR4 and prematurity by collecting blood from 94 mothers of whom 74 delivered prematurely (62 delivered premature singleton infants and 12 premature multiparous). The mothers whose genotypes were analyzed for TLR4 poly-

Table 1. Characteristics of the infants

\begin{tabular}{lcc}
\hline \multicolumn{1}{c}{ Characteristic } & $\begin{array}{c}\text { Premature infants* } \\
(n=440)\end{array}$ & $\begin{array}{c}\text { Term infants } \\
(n=351)\end{array}$ \\
\hline Birth weight $(\mathrm{g}) \dagger$ & $1909 \pm 656$ & $3501 \pm 327$ \\
Gestational age (wk) $\dagger$ & $33.0 \pm 3.5$ & $39.5 \pm 0.9$ \\
Median (range) gestational age & $32.1(23.9-35.9)$ & $39.7(37.0-43.5)$ \\
Gestation $<32.0$ wk at birth, $n(\%)$ & $188(42.7 \%)$ & $0(0.0 \%)$ \\
Male sex & $235(53.4 \%)$ & $179(51.0 \%)$ \\
Multiple births ${ }^{\S}$ & $158(35.9 \%)$ & $6(1.7 \%)$ \\
\hline
\end{tabular}

* Infants born at gestation age of $35 \mathrm{wk}$ or earlier were prospectively analyzed.

$\dagger$ Mean \pm SD. morphism did not carry any of the infants who were the subjects of the present study.

The following diseases or conditions, associated with premature birth, were prospectively included in the analysis: multiple pregnancy (regardless of other pregnancy complication), preeclampsia, PPROM, spontaneous premature birth with or without diagnosis of chorioamnionitis, and placental abruption. Data on sex, gestational age at birth, and neonatal clinical histories were obtained. Of the latter, the association between the incidence of RDS and the TLR4 allele frequencies was studied (16).

Genotyping. Genotyping was performed using allelespecific PCR assays for TLR4 Asp299Gly and TLR4 Thr399Ile polymorphism (17). The PE Taq DNA polymerase kit (Applied Biosystems, Foster City, CA, U.S.A.) was used for PCR reactions. In a total reaction volume of $25 \mu \mathrm{L}, 2.5 \mu \mathrm{L}$ of $10 \times$ PCR buffer, 20 pmol of each primer (see below), $0.02 \mu \mathrm{g}$ of genomic DNA, $5 \mathrm{U}$ of Taq DNA polymerase, and $1 \mu \mathrm{L}$ dNTP mix (CLONTECH, Palo Alto, CA, U.S.A.; stock concentration $10 \mathrm{mM}$ ) were combined. Primers for TLR4 Asp299Gly were forward (F5'GATTAGCATACTTAGACTACTACCTCCATG) and reverse (R5'GATCAACTTCTGAAAAAGCATTCCCAC). Primers for TLR4 Thr399Ile were forward (F5'GGTTGCTGTTCTCAAAGTGATTTTGGGAGAA) and reverse (R5'CCTGAAGACTGGAGAGTGAGTTAAATGCT). The underlined bases in both forward primers indicate the nucleotide altered to create an $\mathrm{NcoI}$ (TLR4 Asp299Gly) and an HinfI (TLR4 Thr399Ile) restriction site, respectively. PCR reactions were run at $95^{\circ} \mathrm{C}$ for $4 \mathrm{~min}$ followed by 30 cycles with a $95^{\circ} \mathrm{C} 30 \mathrm{~s}, 55^{\circ} \mathrm{C} 30 \mathrm{~s}, 72^{\circ} \mathrm{C} 30 \mathrm{~s}$ profile. A $5-\mu \mathrm{L}$ aliquot of the product was digested with the appropriate restriction enzyme and electrophoresed in a $3 \%$ NuSieve (FMC Bioproducts, Rockland, ME, U.S.A.) gel to identify the TLR4 alleles on the basis of the respective allele size. After digestion the wild-type TLR4 allele sizes of $249 \mathrm{bp}$ for the 299 residue and $406 \mathrm{bp}$ for the 399 residue will not change; fragment sizes for carriers of the polymorphic allele will decrease to $23 \mathrm{bp}$ for the 299 residue and $377 \mathrm{bp}$ for the 399 residue.

Statistical analysis. The analysis included only infants with complete data for the following variables: TLR4 genotype, RDS status, gestational age, etiology of premature birth, and sex. Data analysis was performed using the SPSS 9.0 data analysis package (SPSS Inc, Chicago, IL, U.S.A.) for Windows. $\chi^{2}$ analysis or, when appropriate, Fisher's exact test (two-sided analysis) was used as indicated. The results were corrected for multiple comparison. A $p$ value of $<0.05$ was considered as statistically significant. Associations between TLR4 genotype and the different variables were tested for the total infant population and the singleton infants. The observed genotype frequencies were compared with the expected HardyWeinberg distributions by the $\chi^{2}$ analyses.

\section{RESULTS}

Selected population characteristics of the infants are shown in Table 1. There was a strong linkage disequilibrium between the two single nucleotide polymorphisms of TLR4. 299Gly 
associated with 399Ile in $98.6 \%$ of cases. The Asp299Gly polymorphism was chosen for further analysis. The observed genotype distributions did not deviate from the HardyWeinberg equilibrium in any of the study populations.

Frequencies of TLR4 gene variant in fetuses born prematurely and those born at term. The 299Gly allele frequencies in the infants are shown in Table 2. The allele frequencies in premature infants tended to be higher than in the term infants but not significantly so $(p=0.105)$. This difference was significant as compared between premature and term singleton infants $(p=0.024)$. The presenting premature multiples had a lower 299 Gly allele frequency than premature singletons $(p=$ 0.036 ).

Table 3 shows the numbers of prenatal complications and the numbers of the variant allele carrier status among the premature infants. Among premature infants, those with spontaneous premature birth or PPROM and those born prematurely because of severe preeclampsia had apparently similar TLR4 variant frequencies, although owing to low number of cases small differences cannot be detected. Sex, degree of prematurity ( $<32 \mathrm{w}$ and $\geq 32 \mathrm{w}$ ), or diagnosis of RDS had no detectable influence on the frequency of the variant allele (data not shown). In multiple gestations the presenting twins tended to have a lower frequency of 299Gly carrier status than the rest of the premature infants. Table 4 shows the Asp299Gly genotype carrier frequencies in premature and term infants. Similar to allele frequencies, the frequencies of the Asp/Gly or Gly/Gly genotypes were higher in the premature singleton infants than in term singleton infants $(p=0.028)$ or in premature twin infants $(p=0.044)$. This finding further suggests that genetic variation of the TLR4 receptor gene is associated with an increased risk for premature singleton births.

Frequencies of TLR4 gene variant in mothers. Twenty mothers had term singleton delivery, 62 had premature singleton delivery, and 12 had premature multiple delivery. The 299 Gly allele frequencies in these three groups were $7.5 \%$, $13.7 \%$, and $4.2 \%$, and allele carrier frequencies were $15.0 \%$, $24.2 \%$, and $8.4 \%$, respectively. These mothers tended to have similar allele frequencies to the infants in the corresponding birth categories. However, there were no significant differences in the TLR4 allele frequencies among the different groups of mothers. The sample size was too small to define the maternal TLR4 variant as a factor increasing the risk of premature birth.

\section{DISCUSSION}

We have shown here that a previously described polymorphism in the TLR4 receptor gene (TLR4 Asp299Gly and Thr399Ile), related to a blunted airway response to inhaled

Table 2. Frequencies of TLR4 299Gly allele among the genes of preterm and term infant populations*

\begin{tabular}{lcc}
\hline & Preterm population & Term population \\
\hline All infants & $93 / 880(10.6 \%)$ & $58 / 702(8.3 \%)$ \\
Singletons & $70 / 564(12.4 \%)$ & $56 / 690(8.1 \%)$ \\
Multiples & $23 / 316(7.3 \%)$ & $2 / 12(16.7 \%)$ \\
\hline
\end{tabular}

* The total number of alleles is twice as much as the number of infants since each individual has two TLR4 alleles.
Table 3. Number and frequencies of infants according to etiology of prematurity and the TLR4 299 Gly allele carrier status

\begin{tabular}{lcc}
\hline \multicolumn{1}{c}{ Etiology of prematurity } & $\begin{array}{c}\text { Premature infants } \\
n(\% \text { of all })\end{array}$ & $\begin{array}{c}\text { TLR4 } 299 \text { Gly carriers } \\
n(\% \text { of all })\end{array}$ \\
\hline All & $440(100 \%)$ & $90(100 \%)$ \\
Spontaneous vaginal & $105(23.7 \%)$ & $26(28.8 \%)$ \\
Premature rupture of membranes & $102(23.1 \%)$ & $25(27.8 \%)$ \\
Placental abruption & $13(3 \%)$ & $2(2.2 \%)$ \\
Preeclampsia & $62(13.8)$ & $14(14.6 \%)$ \\
Multiple birth & $158(35.7 \%)$ & $23(25.6 \%)$ \\
\hline
\end{tabular}

endotoxin (15), was associated with an increased risk for premature birth in infants. In a population consisting of both preterm and term infants, we show that preterm singleton infants had a significantly higher carrier rate for the TLR4 variant compared with term singleton infants. However, in multiple pregnancies that have a higher prematurity rate than the singleton pregnancies ( $40-60 \%$ versus $5-10 \%)$, the TLR4 variant proportion had no apparent association with prematurity. Inasmuch as the number of multiple term pregnancies carrying the TLR4 polymorphisms was very small $(n=6)$, a larger study involving multiple pregnancies is necessary to clarify whether the TLR4 polymorphism plays a role in causing premature delivery.

The TLR4 receptor is the major transmembrane signaling receptor for LPS. Variant alleles of the TLR4 receptor affecting the immune response to LPS could lead to an increased susceptibility to ascending intrauterine infections. Because standard neonatal care involves the widespread use of antibiotics as part of the preventive treatment, we could not confirm whether the premature infants or the mothers carrying the variant allele in the TLR4 receptor had increased incidence of Gramnegative bacterial infections. Likewise it is not clear whether the increased incidence of premature births in infants expressing genetic variant in the TLR4 receptor was related to the Gram-negative infections or to some labor-producing pattern of the immune response. TLR4 or another TLR receptor may respond to Ureaplasma urealyticum, Gardnerella vaginalis, or anaerobic species often isolated from the amniotic fluid in pregnancies leading to premature birth (2). Mycoplasma, which is related to $U$. urealyticum, is known to signal through the TLR2 receptor (18), but evidence from spirochetes shows that even closely related bacterial species can signal through different Toll-like receptors (19). The variant TLR4 receptor genotype would decrease the acute innate immune response to these pathogens, increasing the susceptibility to microbial invasion. Fetuses carrying certain variants of TLR4, TLR2 (responds predominantly to Gram-positive bacteria), or other genes that influence acute immune response could have a higher risk for premature birth. Prematurity in this case could be related to an altered host defense reaction that precipitates premature labor process, unrelated to the lack of an immune response to specific microbes. Interestingly, in the present population we found a trend toward higher frequency of TLR2 receptor mutations (TLR2 Arg753Gln) in preterm infants compared with term infants (unpublished data). The association was not significant. The TLR2 polymorphism is less frequent 
Table 4. TLR4 Asp299Gly genotype carrier fequencies in premature and term infants and in singleton and multiple births*

\begin{tabular}{|c|c|c|c|}
\hline & $\begin{array}{l}\text { TLR4 Asp299Gly } \\
\text { genotype }\end{array}$ & $\begin{array}{c}\text { Premature infants } \\
\text { rate }(\%)\end{array}$ & $\begin{array}{l}\text { Term infants } \\
\text { rate }(\%)\end{array}$ \\
\hline \multirow[t]{2}{*}{ All infants } & Asp/Asp & $(350 / 440(79.5 \%)$ & $295 / 351(84.0 \%)$ \\
\hline & Asp/Gly & $87 / 440(20.0 \%)$ & $54 / 351(15.4 \%)$ \\
\hline \multirow[t]{3}{*}{ Singleton infants } & Asp/Asp & $215 / 282(76.2 \%)$ & $290 / 345(84.1 \%)$ \\
\hline & Asp/Gly & $64 / 282(22.6 \%)$ & $54 / 345(15.7 \%)$ \\
\hline & Gly/Gly & $3 / 282(1.1 \%)$ & $1 / 345(0.3 \%)$ \\
\hline Multiples & Gly/Gly & $0 / 158(0.0 \%)$ & $1 / 6(16.7 \%)$ \\
\hline
\end{tabular}

* The distribution of genotype frequencies is as expected on the basis of the Hardy-Weinberg distribution.

compared with the TLR4 polymorphism in Caucasian population (allele frequencies $2-4 \%$ versus $5-11 \%$, respectively).

Spontaneous premature birth and prematurity caused by PPROM have been associated with ascending intrauterine infection (1). In the present study, the premature infants as a result of spontaneous birth or PPROM had a higher TLR4 variant allele frequency than the term infants $(p=0.021)$ or the infants born premature as a result of other causes $(p=0.045)$. Multiple factors may precipitate premature birth process. Preeclampsia is characterized by vascular disease and placental insufficiency. In early-onset preeclampsia the frequency of elective premature delivery is increased. Placental villitis and vasculitis are common findings in preeclampsia (20). Although in premature birth caused by preeclampsia the TLR4 variant frequency tended to be high, the frequency was not significantly different from that in term infants or in other groups of premature infants. Multiple pregnancy increases the prematurity rate by one order of magnitude. Excessive uterine stretch is a proposed mechanism. The TLR4 variant allele frequency was not increased in multiples born premature, suggesting that there may be differences between singleton and multiple pregnancies in the mechanisms controlling the labor process.

The mothers who delivered premature singleton infants tended to have a high carrier rate of the variant TLR4 allele. Because of the small sample size, we were unable to determine whether the presence of the TLR4 variant in pregnant mothers is a risk factor for premature birth. It is possible that the genetic TLR4 variant in mother, fetus, or both influence the susceptibility to premature birth. The function of fetal hypothalamicpituitary-adrenal axis may influence the length of pregnancy (21). The role of fetal amnion cells in production of inflammatory mediators in premature labor has been proposed (2). Studies of large populations of pregnant women and their offspring are necessary to better understand the importance of fetal and maternal TLR4 variant as a risk factor of premature birth. Additional studies involving the polymorphism of such genes as CD14, LPS binding protein, and MD-2 may further substantiate the importance of host innate immunity genes as risk factors for pregnancy complications leading to premature birth.

\section{REFERENCES}

1. Goldenberg R, Rouse D 1998 Medical progress: prevention of premature birth. N Engl J Med 339:313-320

2. Gomez R, Ghezzi F, Romero R, Munoz H, Tolosa J, Rojas I 1995 Premature labor and intra-amniotic infection. Clin Perinatol 22:281-342

3. Aderem A 2001 Role of toll-like receptors in inflammatory response in macrophages. Crit Care Med 29(suppl):S16-S18

4. Beutler B, Poltorak A 2001 Sepsis and evolution of the innate immune response. Crit Care Med 29(suppl):S2-S7

5. Deetz DC, Jagielo PJ, Quinn TJ, Thorne PS, Bleuer SA, Schwartz DA 1997 The kinetics of grain dust-induced inflammation of the lower respiratory tract. Am J Respir Crit Care Med 155:254-259

6. Erroi A, Fantuzzi G, Mengozzi M, Sironi M, Orencole SF, Clark BD, Dinarello CA, Isetta A, Gnocchi P, Giovarelli M, Ghezzi P 1993 Differential regulation of cytokine production in lipopolysaccharide tolerance in mice. Infect Immun 61:4356-4359

7. Beutler B, Poltorak A 2000 Positional cloning of LPS and the general role of toll-like receptors in the innate immune response. Eur Cytokine Netw 11:143-152

8. Wright SD 1999 CD14 and innate recognition of bacteria. J Immunol 155:6-8

9. Medzhitov R, Preston-Hurlburt P, Janeway CA 1997 A human homologue of the Drosophila Toll protein signals activation of adaptive immunity. Nature 388:394-397

10. Hallman M, Ramet M, Ezekowitz R 2001 Toll-like receptors as sensors of pathogens. Pediatr Res 50:315-321

11. Poltorak A, He X, Smirnova I, Liu M-Y, Van Huffel C, Du X, Birdwell D, Alejos E, Silva M, Galanos C, Freudenberg M, Ricciardi-Castagnoli P, Layton B, Beutler B 1998 Defective LPS signaling in $\mathrm{C} 3 \mathrm{H} / \mathrm{HeJ}$ and $\mathrm{C} 57 \mathrm{BL} / 10 \mathrm{ScCr}$ mice: mutations in Tlr4 gene. Science 282:2085-2088

12. Takeuchi O, Hoshino K, Kawai T, Sanjo H, Takada H, Ogawa T, Takeda K, Akira S 1999 Differential roles of TLR-2 and TLR-4 in recognition of gram-negative and gram-positive bacterial cell wall components. Immunity 11:443-451

13. Hoshino K, Takeuchi O, Kawai T, Sanjo H, Ogawa T, Takeda Y, Takeda K, Akira S 1999 Cutting edge: Toll-like receptor 4 (TLR4)-deficient mice are hyporesponsive to lipopolysaccharide: evidence for TLR4 as the Lps gene product. J Immunol $162: 3749-3752$

14. Chow JC, Young DW, Golenbock DT, Christ WJ, Gusovsky F 1999 Toll-like receptor-4 mediates lipopolysaccharide-induced signal transduction. J Biol Chem 274:10689-10692

15. Arbour NA, Lorenz E, Schutte BC, Zabner J, Kline JN, Jones M, Frees K, Watt JL, Schwartz DA 2000 TLR4 mutations are associated with endotoxin hyporesponsiveness in humans. Nat Genet 25:187-191

16. Ramet M, Haataja R, Marttila R, Floros J, Hallman M 2000 Association between the surfactant protein A (SP-A) gene locus and respiratory-distress syndrome in the Finnish population. Am J Hum Genet 66:1569-1579

17. Lorenz E, Frees KL, Schwartz DA 2001 Determination of the TLR4 genotype using allele-specific PCR. Biotechniques 31:22-24

18. Nishiguchi M, Matsumoto M, Takao T, Hoshino M, Shimonishi Y, Tsuji S, Begum N, Takeuchi O, Akira S, Toyoshima K, Seya T 2001 Mycoplasma fermentans lipoprotein M161Ag-induced cell activation is mediated by Toll-like receptor 2: role of N-terminal hydrophobic portion in its multiple functions. J Immunol 166:26102616

19. Schroeder NWJ, Optiz B, Lamping N, Michelsen KS, Zaehringer U, Goebel UB, Schumann RR 2000 Involvement of lipopolysaccharide binding protein, CD14, and toll-like receptors in the initiation of innate immune responses by Treponema glycolipids. J Immunol 165:2683-2693

20. Salafia C, Pezullo J, Lopez-Zeno J, Simmens S, Minior V, Vintzileos AM 1995 Placental pathogenic features in preeclampsia. Am J Obstet Gynecol 173:1097-1105

21. Liggins G 2000 The role of the hypothalamic-pituitary-adrenal axis in preparing the fetus for birth. Am J Obstet Gynecol 182:475-477 